\title{
Personalized conditioning and its impact on thermal comfort and energy performance - A review
}

Citation for published version (APA):

Vesely, M., \& Zeiler, W. (2014). Personalized conditioning and its impact on thermal comfort and energy performance - A review. Renewable and Sustainable Energy Reviews, 34, 401-408.

https://doi.org/10.1016/j.rser.2014.03.024

DOI:

10.1016/j.rser.2014.03.024

Document status and date:

Published: 01/01/2014

\section{Document Version:}

Publisher's PDF, also known as Version of Record (includes final page, issue and volume numbers)

\section{Please check the document version of this publication:}

- A submitted manuscript is the version of the article upon submission and before peer-review. There can be important differences between the submitted version and the official published version of record. People interested in the research are advised to contact the author for the final version of the publication, or visit the $\mathrm{DOI}$ to the publisher's website.

- The final author version and the galley proof are versions of the publication after peer review.

- The final published version features the final layout of the paper including the volume, issue and page numbers.

Link to publication

\section{General rights}

Copyright and moral rights for the publications made accessible in the public portal are retained by the authors and/or other copyright owners and it is a condition of accessing publications that users recognise and abide by the legal requirements associated with these rights.

- Users may download and print one copy of any publication from the public portal for the purpose of private study or research.

- You may not further distribute the material or use it for any profit-making activity or commercial gain

- You may freely distribute the URL identifying the publication in the public portal.

If the publication is distributed under the terms of Article 25fa of the Dutch Copyright Act, indicated by the "Taverne" license above, please follow below link for the End User Agreement:

www.tue.nl/taverne

Take down policy

If you believe that this document breaches copyright please contact us at:

openaccess@tue.nl

providing details and we will investigate your claim. 


\title{
Personalized conditioning and its impact on thermal comfort and energy performance - A review
}

\author{
Michal Veselý*, Wim Zeiler \\ Department of Built Environment, Technische Universiteit Eindhoven, P.O. Box 513, 5600 MB Eindhoven, The Netherlands
}

\section{A R T I C L E I N F O}

\section{Article history:}

Received 27 November 2013

Received in revised form

27 February 2014

Accepted 9 March 2014

Available online 30 March 2014

Keywords:

Cooling

Energy performance

Heating

Personalized conditioning

Task ambient conditioning

Thermal comfort

\begin{abstract}
A B S T R A C T
The building industry nowadays is facing two major challenges - the increased concern for energy reduction and the growing need for comfort improvements. These challenges have led many researchers to develop a personalized conditioning system. Personalized conditioning aims to create a microclimate zone around a single workplace. In this way the energy is deployed only where it is actually needed, and the individual needs for thermal comfort are fulfilled. In recent years personalized conditioning has received a lot of attention in research publications. This paper reviews the impact of different personalized conditioning systems on thermal comfort and building energy performance. In the reviewed publications, it was demonstrated that thermal comfort can be well maintained at ambient temperatures that are $4-5 \mathrm{~K}$ higher as well as lower than the temperatures recommended by current standards. Personalized conditioning also allows reduction in energy consumption due to an increased cooling setpoint, a decreased heating setpoint, or a decreased ventilation rate of the background system. Energy simulations show that reductions of up to $60 \%$ can be achieved.
\end{abstract}

(c) 2014 Elsevier Ltd. All rights reserved.

\section{Contents}

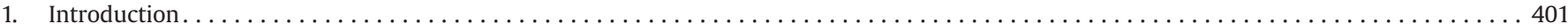

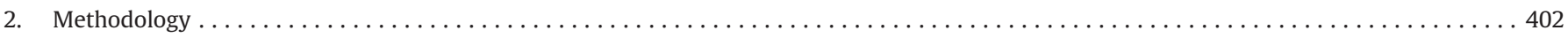

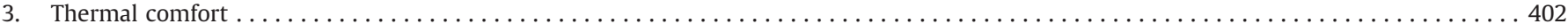

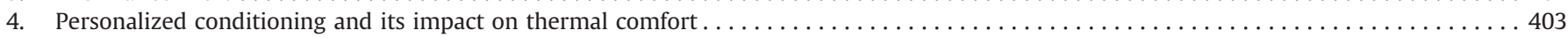

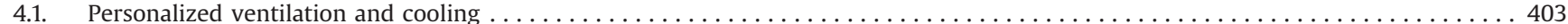

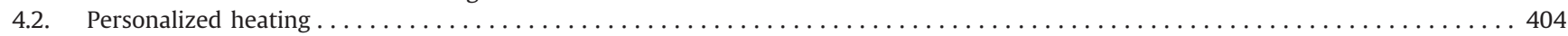

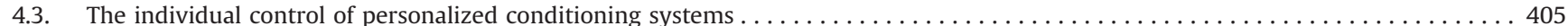

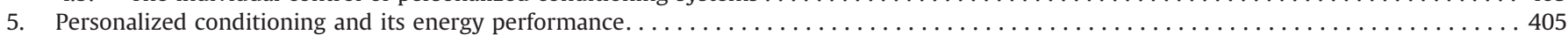

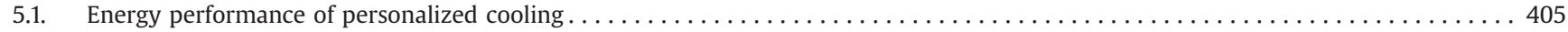

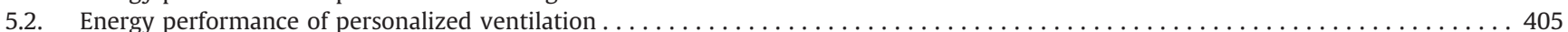

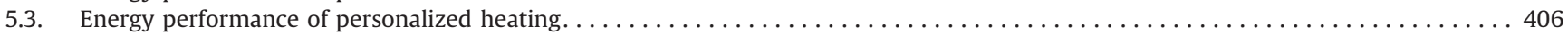

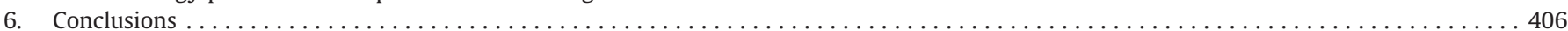

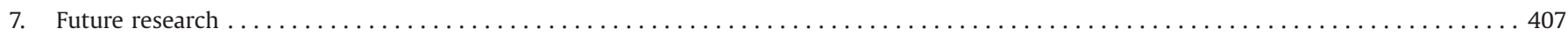

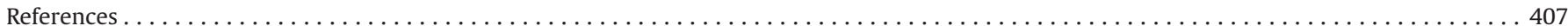

\section{Introduction}

As two of their main functions, buildings protect their occupants against the outdoor weather conditions and provide them a comfortable indoor environment. Mechanical Heating Ventilation and Air

\footnotetext{
* Corresponding author. Tel.: + 31402472039.

E-mail addresses: m.vesely@tuel.nl (M. Veselý),w.zeiler@tue.nl (W. Zeiler).
}

Conditioning (HVAC) is nowadays the main method to provide a comfortable indoor environment, but this has a cost. The built environment accounts for $30 \%$ of the primary energy use in The Netherlands [1] and 20-40\% in the EU and the US [2], while about half of this energy is used by HVAC. Despite the high energy use, a full satisfaction with the indoor environment is often not achieved.

The traditional HVAC design aims to create uniform conditions in the entire conditioned space. The requirements for thermal comfort are prescribed in standards, such as ISO 7730 or ASHRAE 
Standard 55 [3,4], which are based on the average values for a large group of people, who participated in the research done under laboratory conditions. It has been generally assumed that providing an indoor environment preferred by an "average" person ensures the best thermal comfort [5]. In practice the individual differences, based on factors such as age, gender, clothing, activity, or body mass, make it impossible to satisfy the comfort needs of all the occupants using a total volume conditioning [6]. However, controlling the indoor environment in a narrow range around the optimal prescribed by standards does not lead to a higher comfort level [7]. Furthermore in uniform thermal environment only a few body parts are often the source of thermal discomfort, typically the head in warm environments and hands and feet in cool environments $[8,9]$.

The limitations of the traditional approach to HVAC design have led many researchers to design a personalized conditioning system (often also called task ambient conditioning). Personalized conditioning aims to condition only a relatively small space around the user in contrast to the traditional HVAC techniques. Different personalized conditioning systems have been introduced, including personalized ventilation [10], a combination of personalized ventilation with local convective and radiant heating [11,12], a personal environmental module [13], or even a phase change material cooling vest [14]. It has been shown that these systems improve an individual's comfort and reduce the energy consumption when designed and used properly [10-14]. However, despite the positive effects personalized conditioning is still not widespread in the building practice.

This paper starts with the basis of thermal comfort and after this it reviews the impact of personalized conditioning on thermal comfort as well as the energy saving potential of personalized conditioning systems. It is very important to consider these two driving aspects of HVAC design - energy savings and thermal comfort - together without compromising either one.

\section{Methodology}

The scientific databases of ScienceDirect, Web of Science, Wiley Online Library and Taylor and Francis Online were searched for terms related to personalized or task ambient conditioning systems (including ventilation, heating and cooling) and their impact on thermal comfort and building energy performance. The keywords used in the search were personalized, task ambient, local conditioning, ventilation, heating, cooling in combination with thermal comfort, energy use or energy performance. The resulting articles were then reviewed in line with the purpose of the paper. In addition, other relevant publications known to the authors or found through references were also reviewed.

The reviewed publications are sorted into categories of personalized heating, cooling and ventilation. This gives an overview of how well each category is explored and helps to find areas that need further research.

\section{Thermal comfort}

Following the definition by ASHRAE [4] "thermal comfort is that state of mind, which expresses the satisfaction with the thermal environment". The widely used Predicted Mean VotePredicted Percentage of Dissatisfied (PMV-PPD) model developed by Fanger [15] uses six primary factors defining thermal comfort, four of which are related to the environment - air temperature, radiant temperature, air speed and relative humidity - and two individuals - clothing insulation and metabolic activity. In the PMV-PPD model only clothing insulation and metabolic activity are included as individual factors, while other individual factors such as gender, age or body mass are omitted.

The PMV-PPD model [15] is based on a large sample of subjects recruited mostly from college age students. However, facing the increasing number of elderly people in the population, the question arises if it is still applicable for any subpopulation. The elderly do not perceive thermal comfort differently from their younger counterparts, when factors such as activity level or clothing are considered [16-18]. However, the thermoregulation ability tends to decrease with the increasing age [16]. This implies that, even when the preferred temperature is the same for young and elderly, the deviations from the optimum affect the elderly to a greater extent.

A comprehensive literature review on gender differences in thermal comfort by Karjalainen [19] shows that females are generally more likely to express dissatisfaction with their thermal environment. Although no clear difference was revealed in terms of neutral temperature, women seem to be more sensitive to deviations from optimum leading to more complaints, especially in cooler conditions. This is in the line with the findings of Schellen et al. [20] who also reported that particularly for females the skin temperature of the hands is of high importance for overall thermal sensation in cooler conditions.

The lower tolerance of women to the deviations from the optimal temperature range can be explained by the fact that they have, compared to men, generally smaller total and lean body mass, larger body surface and lower resting metabolic rate, although their greater body fat content should allow them to tolerate lower ambient temperatures better [21]. This is supported by the findings of Tikuisis et al. [22] who compared thermoregulatory responses of men and women immersed in cold water. No significant differences occur between the two genders, when the body fatness and the ratio of body surface area to size are taken into account.

Body fat is one of the most important thermophysiological differences between individuals. Both the conduction of heat transfer and blood flow are influenced by body fat. The complex interrelations between human morphology and thermoregulation make it difficult to isolate one component and describe its impact [23]. People with a higher body fat percentage generally have a higher level of activity so they prefer a lower temperature [24].

Savastano [25] studied the core, fingernail bed and abdominal skin temperature of obese and normal weight adults under thermoneutral conditions at rest. The abdominal subcutaneous fat depot was selected because it is the most homogeneous across all participants with regard to the absence of prominent surface vessels. The core temperature did not differ significantly between the obese and normal weight persons. However, infrared thermography-measured fingernail-bed temperature was significantly higher in obese subjects than in normal weight subject. Conversely, the abdominal skin temperature was significantly lower in obese subjects than in normal weight subjects [25]. Increasing heat release from the hands may offset heat retention in areas of the body with greater fat percentage, thereby helping to maintain the normal temperature in obesity. This indicates that the heat loss through the hands of obese subjects increases to compensate for the lower heat loss through the body, where subcutaneous fat is damming the heat losses. The lower heat loss by the insulation layer also explains why obese subjects prefer a lower temperature than normal weight persons. The body pursues a similar core temperature, whether a person is obese or of normal weight.

Another approach to thermal comfort, which has been incorporated in the ASHRAE standard 55 [4], is the adaptive model introduced by de Dear and Brager [26]. The adaptive model is an approach to comfort that starts with the behavioral adaptations 
rather than with the heat exchange theory. This adaptation is a two-way process. People adapt themselves to their thermal environment by changing their clothing insulation, their posture, or their activity. They also adapt their thermal environment to their current requirement by such actions as opening windows, adjusting blinds, and adjusting the heating or cooling. By these adaptations people are in dynamic equilibrium with their surroundings [27].

The partial and whole body thermal sensations of the human body are related to changing skin- and core temperatures. Nonuniformities in environmental conditions (air temperature, air movement, radiation, and conduction to surfaces) affect the skin temperature of the body's various parts, affecting a person's overall thermal sensation and comfort in complex ways. Even in spatially and temporally uniform environments, the body's skin temperatures are distributed non-uniformly [28].

In a uniform thermal environment, the overall thermal sensation follows the local one that is furthest from neutral, and the overall comfort follows the worst local discomfort votes [29]. Thermal sensation and comfort correlate quite well in uniform environments. A neutral sensation correlates to the best comfort; warmer and cooler sensations correlate to reduced comfort. Generally, the head is the most sensitive area of the body in warm conditions and the feet, hands, and back in cool conditions [29].

Thermal environments created by personalized conditioning are often spatially non-uniform or transient. In a non-uniform environment, the influence of the individual body parts on the overall sensation varies greatly. The most influential group consists of the back, chest, and pelvis. Sensations from these body parts have a dominant impact on overall sensation. The least influential group includes the hand and foot at the end of the extremities where vasodilatation and vasoconstriction are strongest $[9,30]$.

In non-uniform environments the relationship between sensation and comfort is more complex. The identical cool face sensation may be perceived as comfortable when the whole body is warm or uncomfortable when the whole body is cold. Therefore, non-uniform environments are not necessarily less desirable than thermal neutrality, but they can actually produce better comfort than a uniform neutral condition.

Zhang [31] found that overall thermal comfort can be based on local comfort only, without any need to include local sensation information. Overall comfort is actually close to the two most uncomfortable votes, so the least comfortable local votes have the most significant influence. Averaging the two least comfortable votes gives the best prediction of the overall comfort. If the subject has some control over his/her thermal environment (e.g., controllable radiant panel) or the thermal conditions are transient, than overall comfort is the average of the two minimum votes and the maximum comfort vote. To keep the whole body comfortable, eliminating the most uncomfortable local votes has the highest priority. This suggests the use of task-ambient systems.

As the individual differences based on age, gender or body fat content show, thermal comfort is not only a simple function of the thermal environment, but it is also influenced by a whole set of individual factors. It is generally very complicated to capture all these influences on thermal comfort and nearly impossible to find an optimal thermal environment for a group of individuals. Thermal neutrality is considered to provide the best comfort, but this does not respect the individual preferences [6]. Therefore, the thermal environment needs to become personalized in order to fit different preferences of each individual.

This paper attempts to investigate by how much the current indoor climate conditions be improved using personalized conditioning. This is based on premise that extension of the range to which indoor air temperature or humidity is controlled would translate to energy savings' potential. However, extreme thermal environment (that is, "too cold" or "too hot") could lead to discomfort levels that cannot be compensated by personalized conditioning. This makes it intuitive to explore the range of indoor climate conditions that can yield energy savings while still ensuring users' thermal comfort.

\section{Personalized conditioning and its impact on thermal comfort}

The conventional HVAC systems create uniform indoor environment and local effects are considered only as a possible source of discomfort in the form of a draft, radiant asymmetry, or vertical temperature gradient. Unlike the conventional HVAC systems, personalized conditioning might expose the building occupant to non-uniform and non-steady-state conditions. A non-uniform thermal environment may provide better comfort than a uniform one in a more energy efficient way [5]. Therefore, there is a need to study the thermal comfort under such combined effects. de Dear et al. [32] reviewed the thermal comfort research over the last twenty years and identified climate chamber studies and field studies as the two main methods to investigate thermal comfort. A growing number of researchers use a new method of comfort simulations [32]. The majority of published research on the impact of personalized conditioning on thermal comfort falls under the category of climate chamber studies and they focus on cooling by an increased air movement. The scientific publications dealing with the impact of personalized conditioning on thermal comfort are summarized in Table 1. The different aspects of personalized conditioning are discussed in the next sections.

\subsection{Personalized ventilation and cooling}

Personalized ventilation aims to supply fresh clean air directly to the breathing zone of the building occupants. It brings two major advantages over the total volume HVAC systems: improved air quality due to higher ventilation effectiveness and potential for cooling due to higher air velocity. The improvements of air quality by personalized ventilation are well documented by a number of studies using a thermal manikin [33-39] as well as human subjects [37,38,40-47].

The thermal comfort research on personalized ventilation focus primarily on warmer environmental conditions and thus on the cooling effect of the higher air movement. Personalized ventilation performs better with regards to the thermal comfort than other methods to elevate the air movement such as standing, ceiling, or desk fans, since it may condition the personalized air in terms of temperature or humidity [10]. It has been shown that with the use of personalized ventilation, thermal comfort can be well maintained at the room air temperatures reaching $30{ }^{\circ} \mathrm{C}[48,49]$ and at a relative humidity of $60-70 \%[46,49]$. Personalized ventilation is not feasible for heating because the elevated air velocity brings a risk of draft discomfort [10].

The current building practice is to avoid higher air velocities as a possible source of draft discomfort. However, newer findings show that the preferences of workers in a typical office building incline much more towards higher rather than lower air movement [50-52]. Zhang et al. [51], based on analysis composed of surveys from more than 200 buildings, report that above the neutral thermal sensation more than $50 \%$ of people would prefer more air movement while less than $2 \%$ people would like decreased air movement. The high dissatisfaction with too little air movement suggests that an increased air velocity might be a reasonable way to improve thermal comfort. 
Table 1

Impact of personalized conditioning on thermal comfort.

\begin{tabular}{|c|c|c|c|c|c|c|c|c|c|}
\hline \multirow[t]{2}{*}{ Reference } & \multicolumn{3}{|c|}{ Functions of the system } & \multicolumn{4}{|c|}{ Type of experiments/evaluation } & \multirow[t]{2}{*}{ Individual control provided } & \multirow{2}{*}{$\begin{array}{l}\text { Ambient } \\
\text { temperatures } \\
\left({ }^{\circ} \mathrm{C}\right)\end{array}$} \\
\hline & Heating & Cooling & Ventilation & $\begin{array}{l}\text { Human } \\
\text { subject/field } \\
\text { study } \\
\text { (number of } \\
\text { subjects) }\end{array}$ & $\begin{array}{l}\text { Thermal } \\
\text { manikin }\end{array}$ & Simulations & $\begin{array}{l}\text { Physical } \\
\text { measurements }\end{array}$ & & \\
\hline [57] & $\checkmark$ & & & & $\checkmark$ & & & - & 18 \\
\hline [45] & $\checkmark$ & & $\checkmark$ & $\checkmark(32)$ & & & & No control & 20 \\
\hline [56] & $\checkmark$ & $\checkmark$ & & $\checkmark(24)$ & & & & No control & $15-45$ \\
\hline [61] & $\checkmark$ & $\checkmark$ & $\checkmark$ & $\checkmark(24)$ & & & & $\begin{array}{l}\text { Flow rate and under some conditions the } \\
\text { direction of personalized air }\end{array}$ & $26-28$ \\
\hline [62] & $\checkmark$ & $\checkmark$ & $\checkmark$ & $\checkmark$ & & & & $\begin{array}{l}\text { Flow rate, direction and temperature of the } \\
\text { personalized air, temperature of the } \\
\text { heating panel }\end{array}$ & $21-25$ \\
\hline$[11]$ & $\checkmark$ & $\checkmark$ & $\checkmark$ & $\checkmark(48)$ & & & & $\begin{array}{l}\text { Flow rate and direction of the personalized air, } \\
\text { the under-desk airflow rate, the temperature of } \\
\text { the convection flow from the chair, and the } \\
\text { surface temperature of the heating panels }\end{array}$ & $20-26$ \\
\hline [12] & $\checkmark$ & $\checkmark$ & $\checkmark$ & & $\checkmark$ & & & - & $20-26$ \\
\hline [48] & $\checkmark$ & $\checkmark$ & $\checkmark$ & $\checkmark(18)$ & & & & $\begin{array}{l}\text { Flow rate of the personalized air, palms and feet } \\
\text { heating levels }\end{array}$ & $18-30$ \\
\hline [63] & & $\checkmark$ & $\checkmark$ & $\checkmark$ & & & & Flow rate and direction of the personalized air & 28 \\
\hline [53] & & $\checkmark$ & $\checkmark$ & $\checkmark(64)$ & & & & Flow rate of the personalized air & $23-26$ \\
\hline [39] & & $\checkmark$ & $\checkmark$ & & $\checkmark$ & $\checkmark$ & & - & 28 \\
\hline [64] & & $\checkmark$ & $\checkmark$ & $\checkmark(24)$ & & & & No control & $23.5-26$ \\
\hline [33] & & $\checkmark$ & $\checkmark$ & & $\checkmark$ & & & - & 26 \\
\hline [35] & & $\checkmark$ & $\checkmark$ & & $\checkmark$ & & & - & 26 \\
\hline [34] & & $\checkmark$ & $\checkmark$ & & $\checkmark$ & & & - & 26 \\
\hline [43] & & $\checkmark$ & $\checkmark$ & $\checkmark(30)$ & & & & Flow rate of the personalized air & $23-26$ \\
\hline [42] & & $\checkmark$ & $\checkmark$ & $\checkmark(60)$ & & & & Flow rate of the personalized air & $23-26$ \\
\hline [65] & & $\checkmark$ & $\checkmark$ & $\checkmark(19)$ & & & & No control & 28.5 \\
\hline [44] & & $\checkmark$ & $\checkmark$ & $\checkmark(30)$ & & & & Flow rate of the personalized air & 26 \\
\hline [68] & & $\checkmark$ & $\checkmark$ & & & $\checkmark$ & $\checkmark$ & - & 26 \\
\hline [67] & & $\checkmark$ & $\checkmark$ & $\checkmark(10)$ & & $\checkmark$ & & No control & $26-28$ \\
\hline [68] & & $\checkmark$ & $\checkmark$ & & $\checkmark$ & & & - & $20-26$ \\
\hline [38] & & $\checkmark$ & $\checkmark$ & $\checkmark(35)$ & & & & No control & $20-26$ \\
\hline [46] & & $\checkmark$ & $\checkmark$ & $\checkmark(30)$ & & & & Flow rate and direction of the personalized air & $23-28$ \\
\hline [37] & & $\checkmark$ & $\checkmark$ & $\checkmark(12)$ & $\checkmark$ & & & No control & 22 \\
\hline [40] & & $\checkmark$ & $\checkmark$ & $\checkmark(11)$ & & & & No control & $23-26$ \\
\hline [41] & & $\checkmark$ & $\checkmark$ & $\checkmark(32)$ & & & & Flow rate of the personalized air & $23.5-26$ \\
\hline [69] & & $\checkmark$ & & $\checkmark(119)$ & & & & Fan speed & $24-31$ \\
\hline [70] & & $\checkmark$ & & & & $\checkmark$ & $\checkmark$ & - & \\
\hline [71] & & $\checkmark$ & & $\checkmark(8)$ & & $\checkmark$ & & Fan speed (under some conditions) & Not reported \\
\hline [54] & & $\checkmark$ & & $\checkmark(32)$ & & & & Fan speed & $22-26$ \\
\hline [49] & & $\checkmark$ & & $\checkmark(16)$ & & & & Fan speed & $26-30$ \\
\hline
\end{tabular}

No problems with draft discomfort caused by personalized ventilation have been reported at temperatures above $23^{\circ} \mathrm{C}$, even when the temperature of the personalized air was $3-4{ }^{\circ} \mathrm{C}$ lower than the room air temperature [10,40-43,53]. At lower temperatures personalized ventilation may cause complaints about draft. However, tests at the room air temperature of $20^{\circ} \mathrm{C}$ did show that heating of the personalized air diminishes the draft discomfort [45].

The concept of personalized ventilation usually uses an additional air distribution system making the whole HVAC system more complicated and costly. However, utilizing the air distribution pattern of displacement ventilation makes it possible to realize a personalized ventilation without any additional centralized ducting. The "ductless" personalized ventilation studied by Halvoňová and Melikov [33-35] sucks the cool clean air distributed in a thin layer over the floor by displacement ventilation and then delivers this air to the breathing zone of the occupants. Since the air supplied by the personalized ventilation is cooler than the air in the occupied zone, more cooling is provided compared to just recirculated room air.

The air movement can also be elevated by personal fans, which means just recirculating of the room air. The tests at room air temperatures of up to $30^{\circ} \mathrm{C}$ show that the thermal comfort can be well maintained using air speeds of as much as $1.5 \mathrm{~m} / \mathrm{s}$ in the upper body region. Another way to generate more air movement is to enhance the natural convective flows around the human body.

A chair equipped with fans to enhance the convective plume has been tested in conjunction with displacement ventilation by Sun et al. [54]. This method provided additional cooling and improved the thermal comfort without the need to decrease the supply temperature of the displacement ventilation, which can lead to risk of draft discomfort.

Even a personalized cooling system incorporated in the clothing has been recently tested. A vest equipped with phase change material improved thermal comfort at rather extreme temperatures, which can occur in the office environment during summer heat waves [14]. However, the applicability of any personalized conditioning system incorporated in clothing is lower because of possible dress codes in the office environment. In this sense the applicability of other means of personalized conditioning is much higher.

\subsection{Personalized heating}

The topic of personalized heating has received less attention in the research literature than personalized cooling. It has been noted 
by Fanger [55] that it is more convenient to provide personalized heating by radiation or conduction, so that the inhaled air may be still kept cool and pleasant to inhale. Most of the personalized heating systems that have been studied use heating elements incorporated in the furniture (chair and desk) and floor or radiation panels and lamps [11,12,48,56,57].

Comparing the heating options of the personalized conditioning system introduced by Melikov and Knudsen [11] identifies the heated chair as a more effective option than floor or under-desk radiant heating panels [12]. The importance of chair heating was also confirmed by Zhang et al. [56] who tested the impact of a heated and cooled seat on thermal comfort. Foda and Sirén [57] have demonstrated that thermal comfort may be maintained at the ambient temperature of $18^{\circ} \mathrm{C}$ by the use of local floor heating. When using a heated chair the comfort ambient temperature can be as low as $15^{\circ} \mathrm{C}[56]$.

The combination of personalized cooling and heating systems such as introduced by Melikov and Knudsen [11], Watanabe et al. [12] and Zhang et al. [48] allows extending the comfort ambient temperature range by $4-5{ }^{\circ} \mathrm{C}$ on the warm and the cool sides [58].

\subsection{The individual control of personalized conditioning systems}

A crucial aspect influencing the performance of any personalized conditioning system is the individual control provided to its user. It has been noted by Zhang et al. [48] that just "being able to control" does not mean automatically improving comfort. The tests of their personalized conditioning system have shown that under more extreme environmental conditions the fixed setting was rated as acceptable as under the user control. However, in less extreme conditions the user control was beneficial with regards to the thermal comfort.

The user is often provided with the control over his or her personalized airflow, temperature of this airflow or temperature of the heating elements (see Table 1). However, this way of control is still highly dependent on user's behavior and can often lead to decreased comfort level and increased energy use. It is therefore desirable to control the conditioning by a critical parameter predicting the changes in user's comfort.

In the cool environments the human body reduces the blood flow in the body extremities in the process called vasoconstriction [59]. This process results in a considerable drop in a skin temperature of the body extremities, particularly hands, and often leads to cool discomfort [59]. Since the hands dictate the thermal comfort in cool environments [59], the hand skin temperature has a potential to become a critical parameter for control of a local heating system. This idea has been tested by Vissers [60] who used finger temperature, sensed remotely by an infrared camera, as a control signal for local radiant heating. Although this study shows promising results, it has strong limitations in terms of the low number of human subjects participating in the experiments and a control process that was not fully automated. Further investigation on this topic is thus needed.

\section{Personalized conditioning and its energy performance}

The personalized conditioning aims to provide a comfortable and healthy environment locally and with respect to individual need of the users. The local approach also gives the potential for energy savings, which can be achieved in several ways

1. by extending the temperature setpoints for the whole space while the thermal comfort is well maintained by local heating or cooling;
2. by reducing the outdoor airflow rate, which is compensated for by substantially higher ventilation effectiveness of the personalized ventilation;

3. by running the personalized conditioning system only when the occupant is present at his or her workplace.

The energy savings estimated by different studies of personalized conditioning systems are listed in Table 2 and range from 4 to $60 \%$. All the studies listed in the table are based on calculations or dynamic energy simulations. The energy saving percentages listed in the table are difficult to compare because of different assumptions made in the studies in terms of the building and HVAC design, the climate conditions, and operational strategy. Generally it is reasonable to compare only the energy savings achieved with the same system functions and in the same climate. Nevertheless this overview shows that building energy consumption may be reduced considerably using personalized conditioning.

\subsection{Energy performance of personalized cooling}

Most of the reviewed studies focus on cooling in hot climates $[48,66,67,70-74]$. Personalized convective cooling is applied in all the reviewed studies concerning cooling, often in combination with personalized ventilation. In these studies the most common strategy for reducing the energy use is to increase the temperature setpoint for the total volume conditioning while the comfort is still well maintained by the personalized cooling. The estimated energy savings vary between 4 and 51\% when the cooling setpoint is increased by $2.5-6{ }^{\circ} \mathrm{C}$. It has to be noted that the highest energy savings of $51 \%$ are achieved by the combination of increased cooling setpoint and reduced airflow rate [74].

Hoyt et al. [75] studied the energy saving potential of increasing the cooling setpoint in several cities in the US. Although this study does not include the use of personalized conditioning, it can give an idea about potential energy savings when using low powered personalized cooling. Fig. 1 compares estimated energy savings in hot climates by studies [40,48,66,67,70,73-76]. Only the energy savings achieved in hot climates are included for studies $[48,73]$. Studies $[71,72]$ are not included in the chart because they do not clearly state the cooling setpoint increment. Fig. 1 shows that most of the values cluster around a cooling setpoint raised by $3{ }^{\circ} \mathrm{C}$ resulting in energy savings of approx. 30\%. The only exception in this trend is the study by Yang et al. [76], which reports exceptionally low energy reduction by increased cooling setpoint. This is caused by outdoor relative humidity of $80 \%$ and indoor relative humidity setpoint of $50 \%$. The biggest part of cooling energy is accounted for in this case by dehumidification. Raising the indoor relative humidity setpoint in humid climates might be a more effective strategy to save energy than just raising the indoor air temperature setpoint. The thermal comfort can still be well maintained under ambient relative humidity of up to 70\% [46,49].

Ghaddar et al. [71] presented an energy saving strategy based on undersizing the total volume cooling system consisting of chilled ceiling and displacement ventilation. The transient thermal discomfort during peak hours is compensated by the personalized cooler. The total volume conditioning system, undersized by $25 \%$ and simulated for an office space in a hot climate, is able to meet the load $80 \%$ of the time. The lower capacity chiller works at better efficiency since most of the time it operates close to full load while the higher capacity system runs most of the day at a partial load. This results in energy savings of about 7\% [71].

\subsection{Energy performance of personalized ventilation}

Comparing energy performance of the personalized ventilation in hot [74] and cold [77] climates shows that different energy 
Table 2

Energy performance of personalized conditioning.

\begin{tabular}{|c|c|c|c|c|c|}
\hline Reference & Type of personalized conditioning & $\begin{array}{l}\text { Personalized } \\
\text { conditioning } \\
\text { functions }\end{array}$ & Tested conditions & $\begin{array}{l}\text { Estimated energy } \\
\text { savings }\end{array}$ & Saving strategy \\
\hline [70] & Personalized evaporative cooler & Cooling & Hot climate & $18 \%$ & $\begin{array}{l}\text { Supply temperature of displacement ventilation } \\
\text { raised from } 21 \text { to } 24^{\circ} \mathrm{C}\end{array}$ \\
\hline [71] & Personalized evaporative cooler & Cooling & Hot climate & $7 \%$ & $\begin{array}{l}\text { Undersized overall cooling system compensated by } \\
\text { personalized cooler during transient periods }\end{array}$ \\
\hline [67] & $\begin{array}{l}\text { Ceiling-mounted personalized } \\
\text { ventilation }\end{array}$ & Cooling, ventilation & Hot climate & $34 \%$ & $\begin{array}{l}\text { Cooling setpoint raised from } 24.5 \text { to } 28{ }^{\circ} \mathrm{C} \text { with } \\
\text { personalized ventilation supplying the air at } 16{ }^{\circ} \mathrm{C}\end{array}$ \\
\hline [66] & $\begin{array}{l}\text { Ceiling-mounted personalized } \\
\text { ventilation }\end{array}$ & Cooling, ventilation & Hot climate & $30 \%$ & $\begin{array}{l}\text { Cooling setpoint raised from } 23 \text { to } 26^{\circ} \mathrm{C} \text { with } \\
\text { personalized ventilation supplying the air at } 20{ }^{\circ} \mathrm{C}\end{array}$ \\
\hline [72] & Partition based personalized cooler & Cooling, ventilation & Hot climate & $45 \%$ & $\begin{array}{l}\text { Cooling setpoint raised (study compares the } \\
\text { performance of central and personalized system } \\
\text { controlled be PMV index) }\end{array}$ \\
\hline [73] & Personal fan/personalized ventilation & Cooling, ventilation & Cold to hot climate & $\begin{array}{l}\text { Up to } 33 \% \text { (hot } \\
\text { climate) and up to } \\
48 \% \text { (cold climate) }\end{array}$ & $\begin{array}{l}\text { Cooling setpoint raised by } 2.5^{\circ} \mathrm{C} \text {, actual energy } \\
\text { savings depend on the power consumption of the } \\
\text { personal fan }\end{array}$ \\
\hline [77] & Personalized ventilation & Cooling, ventilation & Cold climate & $60 \%$ & $\begin{array}{l}\text { Cooling setpoint raised from } 25.5^{\circ} \mathrm{C} \text { to } 30{ }^{\circ} \mathrm{C} \text { with } \\
\text { personalized ventilation supplying the air at } 20^{\circ} \mathrm{C}\end{array}$ \\
\hline [74] & Personalized ventilation & Cooling, ventilation & Hot climate & $51 \%$ & $\begin{array}{l}\text { Cooling setpoint raised from } 24^{\circ} \mathrm{C} \text { to } 28^{\circ} \mathrm{C} \text {, reduced } \\
\text { airflow rate due to higher ventilation effectiveness }\end{array}$ \\
\hline [40] & Personalized ventilation & Cooling, ventilation & Hot climate & $30 \%$ & $\begin{array}{l}\text { Cooling setpoint raised from } 24^{\circ} \mathrm{C} \text { to } 28^{\circ} \mathrm{C} \text {, reduced } \\
\text { airflow rate due to higher ventilation effectiveness }\end{array}$ \\
\hline [76] & $\begin{array}{l}\text { Ceiling-mounted personalized } \\
\text { ventilation }\end{array}$ & Cooling, ventilation & Hot climate & $4 \%$ & $\begin{array}{l}\text { Cooling setpoint raised from } 23.5^{\circ} \mathrm{C} \text { to } 26^{\circ} \mathrm{C} \text { with } \\
\text { personalized ventilation supplying the air at } 23.5^{\circ} \mathrm{C}\end{array}$ \\
\hline [48] & $\begin{array}{l}\text { Combination of personalized } \\
\text { ventilation, palms and feet heating } \\
\text { and hand cooling }\end{array}$ & $\begin{array}{l}\text { Cooling, heating, } \\
\text { ventilation }\end{array}$ & Mild to hot climate & Up to $44 \%$ & $\begin{array}{l}\text { Heating setpoint lowered from } 21.5^{\circ} \mathrm{C} \text { to } 18^{\circ} \mathrm{C} \text { and } \\
\text { cooling setpoint raised from } 24{ }^{\circ} \mathrm{C} \text { to } 30{ }^{\circ} \mathrm{C}\end{array}$ \\
\hline [57] & Local floor heating & Heating & Not specified & $17 \%$ & Heating setpoint lowered from $21^{\circ} \mathrm{C}$ to $18^{\circ} \mathrm{C}$ \\
\hline [60] & Personalized radiant heating & Heating & Mild climate & $17 \%$ & Heating setpoint lowered from $22{ }^{\circ} \mathrm{C}$ to $19.5^{\circ} \mathrm{C}$ \\
\hline
\end{tabular}

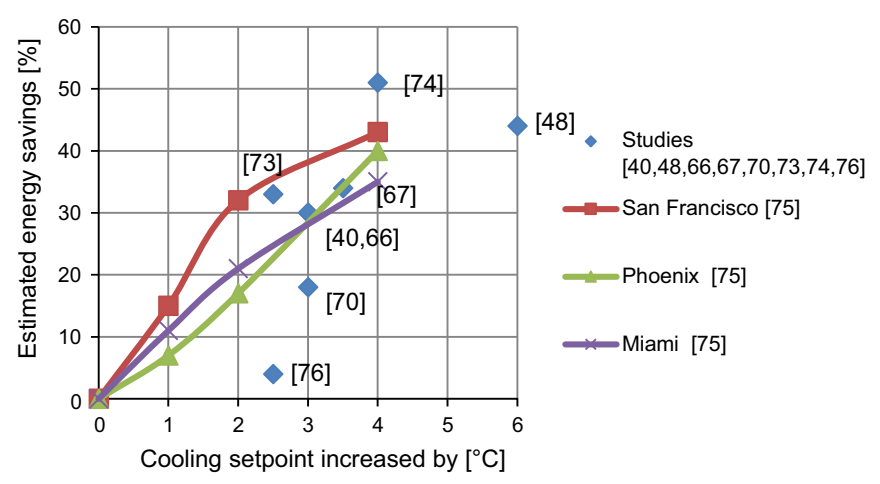

Fig. 1. Comparison of estimated energy savings in hot climates by studies $[40,48,66,67,70,73-76]$.

saving strategies have to be applied in different climate conditions. Unlike increasing the cooling setpoint, which works in both climates, reducing the airflow rate does not always imply a reduction of the energy consumption in cold climates because the outdoor air has a free cooling effect in a building that mainly needs cooling [77]. Higher relative energy savings were achieved in cold climate (up to $60 \%$ according to Ref. [77]). However, this has to be understood in the context of the reference cases. The cooling energy need of a reference case is much lower in the cold than in the hot climate, so even higher relative energy savings do not mean higher savings in the absolute energy consumption.

Schiavon et al. [73] investigated how the power consumption of a personal fan influences the energy savings due to the increased cooling setpoint. Under conditions considered in their study (cold to hot climate, cooling setpoint increased by $2.5^{\circ} \mathrm{C}$ ), it was never possible to achieve energy savings with a personal fan input power higher than $60 \mathrm{~W}$. Calculations made for the best guess values for a coefficient of performance of the chiller of 3.5 and energy losses from emission, distribution and storage for cooling of 0.05 (common values from practical experience) reveal that energy savings are not be achieved with fans using more than $20 \mathrm{~W}$ [73]. This suggests that the power input of personalized conditioning is a critical factor for the applicability as an energy saving solution in practice.

\subsection{Energy performance of personalized heating}

In contrast to studies on personalized cooling only a few studies deal with personalized heating as an energy saving solution. The studies of Foda and Sirén [57] and Vissers [60] both report energy savings of $17 \%$ of heating energy, when the heating setpoint of the total volume heating was decreased by $3{ }^{\circ} \mathrm{C}$ [57], resp. $2.5^{\circ} \mathrm{C}[60]$ and the energy consumption of the local floor heating [57], resp. personalized radiant heating [60] was taken into account.

The system presented in the study of Zhang et al. [48] also included personalized heating, but the annual energy savings of $40 \%$ were reported only for the whole combination of personalized heating and cooling, while the dead-band was extended from $21.5-24{ }^{\circ} \mathrm{C}$ to $18-30{ }^{\circ} \mathrm{C}$.

\section{Conclusions}

An individual approach to the building occupants makes it possible to satisfy different needs of different persons and thus improves comfort and subsequently also health and performance.

In the reviewed studies, it was demonstrated that elevated air movement is an effective way to provide local cooling. Thermal comfort is well preserved in the ambient temperature of up to $30{ }^{\circ} \mathrm{C}$ and relative humidity of up to $70 \%$ when personalized convective cooling is applied. However, no publication was found reporting a threshold above which a satisfactory thermal comfort cannot be achieved by elevated air movement. Among the methods to elevate the air movement, personalized ventilation has several advantages over personal fans. Personalized ventilation 
can condition the supplied air in terms of temperature and humidity. Therefore lower air velocity is needed to create a sufficient cooling effect, which lowers the risk of draft or irritation due to air movement. Personalized ventilation provides fresh air, improving thus also the indoor air quality.

Two basic principles are feasible to provide personalized heating - radiation by panels or lamps and conduction by heated chair or heated floor or heated desk mats. A comprehensive comparison of the personalized heating is missing, although some experiments showed that a heated chair is preferred by users. The ambient temperatures, under which it is possible to maintain thermal comfort with the use of personalized conditioning, were reported to be as low as $15{ }^{\circ} \mathrm{C}$.

Beside comfort improvements, personalized conditioning also reduces energy consumption due to higher effectiveness compared to traditional HVAC design - the energy is deployed where it is actually needed. The energy saving potential reported in literature reaches up to $60 \%$ using personalized ventilation with lowered cooling setpoint and reduced airflow rate. Extending the temperature dead-band to $18-30{ }^{\circ} \mathrm{C}$ with the use of a combination of personalized heating and cooling can lead to annual energy savings of about $40 \%$.

\section{Future research}

As shown in this paper personalized conditioning brings advantages over total volume conditioning in terms of improved thermal comfort and reduced energy consumption. However, several topics still remains to be explored in order to ease practical application of personalized conditioning. Some of these topics are outlined as follows:

- It has been reported that the energy consumption of the personalized conditioning system is a critical factor for its applicability as an energy saving solution. Therefore, there is a need for development of low power personalized conditioning systems.

- Different personalized conditioning systems have been introduced, but a comprehensive comparison of different options for heating and cooling is still missing. Such a comparison can be made by introducing an efficiency that relates cooling or heating effect and energy consumption of the personalized conditioning system. The cooling or heating effect can be represented by difference in thermal sensation or skin temperature with and without personalized conditioning. This would provide an easy to use parameter for comparing different systems by HVAC designers.

- Individual control of personalized conditioning is nowadays based solely on user interaction. This can lead to negative effects such as rebound or overshoot. Therefore, it is needed to investigate the possibility to incorporate physiological parameters that can predict thermal discomfort into control loop.

- While most of the papers included in this review were based on experiments in the climate chambers or on simulations, only a few studies presented field tests. Evaluation of personalized conditioning in real conditions thus remains to be done.

\section{References}

[1] Ministry of Economic Affairs. Agriculture and innovation. Energy report. The Hague; 2011.

[2] Pérez-Lombard L, Ortiz J, Pout C. A review on buildings energy consumption information. Energy Build 2008;40:394-8.
[3] International Standard Organisation, ISO 7730. Ergonomics of the thermal environment - analytical determination and interpretation of thermal comfort using calculation of the PMV and PPD indices and local thermal comfort criteria; 2005.

[4] ASHRAE, Standard 55-2004. Thermal environmental conditions for human occupancy. Atlanta (GA); 2004

[5] de Dear R. Revisiting an old hypothesis of human thermal perception: alliesthesia. Build Res Inf 2011;39:108-17.

[6] van Hoof J. Forty years of Fanger's model of thermal comfort: comfort for all? Indoor Air 2008;18:182-201.

[7] Arens E, Humphreys Ma, de Dear R, Zhang H. Are "class A" temperature requirements realistic or desirable? Build Environ 2010;45:4-10.

[8] Yao Y, Lian Z, Liu W, Shen Q. Experimental study on skin temperature and thermal comfort of the human body in a recumbent posture under uniform thermal environments. Indoor Built Environ 2007;16:505-18.

[9] Wang D, Zhang H, Arens E, Huizenga C. Observations of upper-extremity skin temperature and corresponding overall-body thermal sensations and comfort. Build Environ 2007;42:3933-43.

[10] Melikov AK. Personalized ventilation. Indoor Air 2004;14:157-67.

[11] Melikov AK, Knudsen GL. Human response to an individually controlled microenvironment. HVAC\&R Res 2007;13:645-60.

[12] Watanabe S, Melikov AK, Knudsen GL. Design of an individually controlled system for an optimal thermal microenvironment. Build Environ 2010;45:549-58.

[13] Demeter M, Wichman P. Personal environmental module; 1993.

[14] Gao C, Kuklane K, Wang F, Holmér I. Personal cooling with phase change materials to improve thermal comfort from a heat wave perspective. Indoor Air 2012;22:523-30.

[15] Fanger PO. Thermal comfort. Analysis and applications in environmental engineering. Copenhagen, Denmark: Copenhagen Danish Tech. Press; 1970.

[16] Havenith G. Temperature regulation and technology. Gerontechnology $2001 ; 1: 41-9$

[17] van Hoof J, Hensen J. Thermal comfort and older adults. Gerontechnology 2006:4(4):223-8.

[18] DeGroot D, Havenith G, Kenney W Larry. Responses to mild cold stress are predicted by different individual characteristics in young and older subjects. J Appl Physiol 2006;101:1607-15.

[19] Karjalainen S. Thermal comfort and gender: a literature review. Indoor Air 2012;22:96-109.

[20] Schellen L, Loomans MGLC, de Wit MH, Olesen BW, van Marken Lichtenbelt WD. The influence of local effects on thermal sensation under non-uniform environmental conditions - gender differences in thermophysiology, thermal comfort and productivity during convective and radiant cooling. Physiol Behav 2012;107:252-61.

[21] Kaciuba-Uscilko H, Grucza R. Gender differences in thermoregulation. Curr Opin Clin Nutr Metab Care 2001;4:533-6.

[22] Tikuisis P, Jacobs I, Moroz D, Vallerand AL, Martineau L. Comparison of thermoregulatory responses between men and women immersed in cold water. J Appl Physiol 2000;89:1403-11.

[23] Anderson GS. Human morphology and temperature regulation. Int J Biometeorol 1999;43:99-109.

[24] Zhang H, Huizenga C, Arens E, Yu T. Considering individual physiological differences in a human thermal model. J Therm Biol 2001;26:401-8.

[25] Savastano D, Gorbach A. Adiposity and human regional body temperature. Am J Clin Nutr 2009:1124-31.

[26] de Dear R, Brager G. Developing an adaptive model of thermal comfort and preference. ASHRAE Trans 1998;104:145-67.

[27] Humphreys MA, Rijal HB, Nicol JF. Updating the adaptive relation between climate and comfort indoors; new insights and an extended database. Build Environ 2013;63:40-55.

[28] Huizenga C, Zhang H, Arens E, Wang D. Skin and core temperature response to partial- and whole-body heating and cooling. J Therm Biol 2004:29:549-58.

[29] Arens E, Zhang H, Huizenga C. Partial- and whole-body thermal sensation and comfort - Part I: uniform environmental conditions. J Therm Biol 2006:31:53-9.

[30] Zhang H. Human thermal sensation and comfort in transient and non-uniform thermal environments. Berkeley: University of California; 2003.

[31] Zhang H, Arens E, Huizenga C, Han T. Thermal sensation and comfort models for non-uniform and transient environments, Part III: Whole-body sensation and comfort. Build Environ 2010;45:399-410.

[32] de Dear R, Akimoto T, Arens E, Brager G, Candido C, Cheong KWD, et al. Progress in thermal comfort research over the last twenty years. Indoor Air 2013;23:442-61.

[33] Halvoňová B, Melikov AK. Performance of "ductless" personalized ventilation in conjunction with displacement ventilation: impact of disturbances due to walking person(s). Build Environ 2010;45:427-36.

[34] Halvoňová B, Melikov AK. Performance of ductless personalized ventilation in conjunction with displacement ventilation: impact of workstations layout and partitions. HVAC\&R Res 2010;16:75-95.

[35] Halvoňová B, Melikov AK. Performance of "ductless" personalized ventilation in conjunction with displacement ventilation: impact of intake height. Build Environ 2010;45:996-1005.

[36] Cermak R, Melikov AK, Forejt L, Kovar O. Performance of personalized ventilation in conjunction with mixing and displacement ventilation. HVAC\&R Res 2006;12:295-311.

[37] Niu J, Gao N, Phoebe M, Huigang Z. Experimental study on a chair-based personalized ventilation system. Build Environ 2007;42:913-25. 
[38] Melikov AK, Ivanova T, Stefanova G. Seat headrest-incorporated personalized ventilation: thermal comfort and inhaled air quality. Build Environ 2012;47:100-8.

[39] Conceição EZE, Lúcio MMJR, Rosa SP, Custódio ALV, Andrade RL, Meira MJP a. Evaluation of comfort level in desks equipped with two personalized ventilation systems in slightly warm environments. Build Environ 2010;45:601-9.

[40] Sekhar C, Gong N, Tham K, Cheong KWD, Melikov AK, Wyon DP, et al. Findings of personalized ventilation studies in a hot and humid climate. HVAC\&R Res 2005;11:603-20.

[41] Yang B, Sekhar C, Melikov AK. Ceiling-mounted personalized ventilation system integrated with a secondary air distribution system - a human response study in hot and humid climate. Indoor Air 2010;20:309-19.

[42] Kaczmarczyk J, Melikov AK, Fanger PO. Human response to personalized ventilation and mixing ventilation. Indoor Air 2004;14(Suppl 8):S17-29.

[43] Kaczmarczyk J, Melikov AK, Bolashikov Z, Nikolaev L, Fanger PO. Human response to five designs of personalized ventilation. HVAC\&R Res 2006:37-41.

[44] Li R, Sekhar C, Melikov AK. Thermal comfort and IAQ assessment of underfloor air distribution system integrated with personalized ventilation in hot and humid climate. Build Environ 2010;45:1906-13.

[45] Kaczmarczyk J, Melikov AK, Sliva D. Effect of warm air supplied facially on occupants' comfort. Build Environ 2010;45:848-55.

[46] Melikov AK, Skwarczynski Ma, Kaczmarczyk J, Zabecky J. Use of personalized ventilation for improving health, comfort, and performance at high room temperature and humidity. Indoor Air 2013;23:250-63.

[47] Melikov AK, Kaczmarczyk J. Air movement and perceived air quality. Build Environ 2012;47:400-9.

[48] Zhang H, Arens E, Kim D, Buchberger E, Bauman F, Huizenga C. Comfort, perceived air quality, and work performance in a low-power task-ambient conditioning system. Build Environ 2010;45:29-39.

[49] Zhai Y, Zhang H, Zhang Y, Pasut W, Arens E, Meng Q. Comfort under personally controlled air movement in warm and humid environments. Build Environ 2013;65:109-17.

[50] Toftum J. Air movement - good or bad? Indoor Air 2004;14(Suppl 7):S40-5.

[51] Zhang H, Arens E, Fard SA, Huizenga C, Paliaga G, Brager G, et al. Air movement preferences observed in office buildings. Int $\mathrm{J}$ Biometeorol 2007;51:349-60.

[52] Hoyt T, Zhang H, Arens E. Draft or breeze? Preferences for air movement in office buildings and schools from the ASHRAE database. In: Proceedings of healthy buildings; 2009. p. 3-7.

[53] Chen Y, Raphael B, Sekhar C. Individual control of a personalized ventilation system integrated with an ambient mixing ventilation system. HVAC\&R Res 2012; $18: 1136-52$

[54] Sun W, Cheong KWD, Melikov AK. Subjective study of thermal acceptability of novel enhanced displacement ventilation system and implication of occupants' personal control. Build Environ 2012;57:49-57.

[55] Fanger PO. Human requirements in future air-conditioned environments. Int J Refrig 2001:24:148-53.

[56] Zhang YF, Wyon DP, Fang L, Melikov AK. The influence of heated or cooled seats on the acceptable ambient temperature range. Ergonomics 2007:50:586-600.
[57] Foda E, Sirén K. Design strategy for maximizing the energy-efficiency of a localized floor-heating system using a thermal manikin with human thermoregulatory control. Energy Build 2012;51:111-21.

[58] Zhang H, Arens E, Pasut W. Air temperature thresholds for indoor comfort and perceived air quality. Build Res Inf 2011;39:134-44.

[59] Arens E, Zhang H. The skin's role in human thermoregulation and comfort. In: Pan N, Gibson P, editors. Thermal and moisture transport in fibrous materials, Woodhead Publishing Ltd; 2006. p. 560-602.

[60] Vissers DR. The human body as sensor for thermal comfort control. Eindhoven University of Technology; 2012.

[61] Amai H, Tanabe S, Akimoto T, Genma T. Thermal sensation and comfort with different task conditioning systems. Build Environ 2007;42:3955-64.

[62] Bauman F, Carter T, Baughman A. Field study of the impact of a desktop task/ ambient conditioning system in office buildings. ASHRAE Trans 1998;104:1153-71.

[63] Akimoto T, Tanabe S, Yanai T, Sasaki M. Thermal comfort and productivity evaluation of workplace environment in a task conditioned office. Build Environ 2010;45:45-50.

[64] Gong N, Tham K, Melikov AK, Wyon DP, Sekhar C, Cheong KWD. The acceptable air velocity range for local air movement in the tropics. HVAC\&R Res 2006;12:1065-76.

[65] Kalmár F, Kalmár T. Alternative personalized ventilation. Energy Build 2013;65:37-44.

[66] Makhoul A, Ghali K, Ghaddar N. Desk fans for the control of the convection flow around occupants using ceiling mounted personalized ventilation. Build Environ 2013;59:336-48.

[67] Makhoul A, Ghali K, Ghaddar N. Thermal comfort and energy performance of a low-mixing ceiling-mounted personalized ventilator system. Build Environ 2013;60:126-36

[68] Melikov AK, Cermak R, Majer M. Personalized ventilation: evaluation of different air terminal devices. Energy Build 2002;34:829-36.

[69] Arens E, Xu T, Miura K, Zhang H, Fountain M, Bauman F. A study of occupant cooling by personally controlled air movement. Energy Build 1998;27:45-59.

[70] Chakroun W, Ghaddar N, Ghali K. Chilled ceiling and displacement ventilation aided with personalized evaporative cooler. Energy Build 2011:43:3250-7.

[71] Ghaddar N, Ghali K, Chakroun W. Evaporative cooler improves transient thermal comfort in chilled ceiling displacement ventilation conditioned space. Energy Build 2013;61:51-60.

[72] Pan C-S, Chiang H-C, Yen M-C, Wang C-C. Thermal comfort and energy saving of a personalized PFCU air-conditioning system. Energy Build 2005;37:443-9.

[73] Schiavon S, Melikov AK. Energy saving and improved comfort by increased air movement. Energy Build 2008;40:1954-60.

[74] Schiavon S, Melikov AK, Sekhar C. Energy analysis of the personalized ventilation system in hot and humid climates. Energy Build 2010;42:699-707.

[75] Hoyt T, Lee K, Zhang H, Arens E, Webster T. Energy savings from extended air temperature setpoints and reductions in room air mixing. In: Proceedings of the international conference on environmental ergonomics; 2009.

[76] Yang B, Sekhar C, Melikov AK. Ceiling mounted personalized ventilation system in hot and humid climate - an energy analysis. Energy Build 2010;42:2304-8.

[77] Schiavon S, Melikov AK. Energy-saving strategies with personalized ventilation in cold climates. Energy Build 2009:41:543-50. 